\title{
Os espaços/tempos da pesquisa sobre o professor
}

Janete Magalhães Carvalho

Universidade Federal do Espírito Santo

\section{Resumo}

Analisa como a questão do professor se apresenta na produção científica brasileira. Toma como base o discurso apresentado na SBPC, por, entre outros fatores, ser originário de entidade que congrega cientistas de todas as áreas de conhecimento e ser representativo da produção docente e discente de graduação e pós-graduação das várias regiões e instituições do país. Usa como metodologia a abordagem histórico-documental. Utiliza como fontes os resumos publicados nos anais de 2001 e da década de 1980. Os resultados evidenciam: 1) um aumento extraordinário do número de trabalhos sobre o professor, a permanência da origem institucional (universidade pública) e territorial (Sudeste); 2) alteração do predomínio do enfoque temático, da formação do professor, em nível superior e médio, para a prática pedagógica exercida no cotidiano escolar do ensino fundamental; 3) alteração no enfoque metodológico, passando dos estudos exploratório-descritivos para a pesquisa-ação crítica voltada para a intervenção no cotidiano escolar do ensino fundamental. Conclui pela negação dos espaços/tempos da produção científica sobre o professor, visto que os espaços/tempos são ações de sujeitos históricos, que exibem operações de troca, intercâmbios, compartilhamentos coletivos e não a determinação do "lugar próprio" do pesquisador e/ou da "autoria marcada". Os discursos expressos pareceram, cada um, ocupar um "lugar próprio" e isolado, não permitindo a sua acepção como conjunto da obra sobre a questão do professor, não se vislumbrando uma tessitura temática coletiva, com gênese nos espaços/tempos da academia em sua relação com a realidade educacional e social do Brasil.

\section{Palavras-chave}

Espaço/tempo - Produção científica - Professor 


\section{The spaces/times of the research on teachers}

Janete Magalhães Carvalho

Federal University of Espirito Santo

Correspondence:

Janete Magalhães Carvalho

Rua Benedito Mello Serrano, 215

29.065-040 - Vitória - ES

e-mail: janetemc@terra.com.br

\section{Abstract}

The article analyzes how the issue of the teacher appears in the Brazilian scientific literature. It is based on the discourse found at the Brazilian Society for the Progress of Science (SBPC) Meetings, a society that congregates scientists from all areas of knowledge, and is representative of the scientific production of teachers and graduate students from various Brazilian regions and institutions. The work makes use of a historical-documental approach; its sources of information are the abstracts published in the Society's Annals of 2001 and from the 1980s.

Results show: a. an extraordinary increase in the number of papers on the teacher, and the continuing evidence of their institutional (public university) and regional (Southeastern) origin; b. a change of emphasis in the themes, from the education of higher education teachers to the pedagogical practice that takes place in the Elementary School everyday life; c. a change in the methodological approach, from the exploratory-descriptive studies to the critical research-action concerned with the intervention in the Elementary School everyday life.

The article asserts the negation of the spaces/times of the scientific production on the teacher, because spaces/times are actions of historical agents, exhibiting exchanges and collective sharing, and not the determination of the "proper place" of the researcher and/or of "stamped authorship". The discourses presented seemed, each one of them, to occupy their isolated "proper place", preventing their understanding as the whole of the work on the issue of the teacher, failing to reveal the fabric of a collective theme with its genesis in the spaces/times of the academy in its relationship with the social and educational reality of Brazil.

\section{Keywords}

Space/time - Scientific production - SBPC - Teacher. 
A noção da distância que há entre o discurso acadêmico e a escola pública fundamental implica a difícil avaliação de algo no qual estamos imersos, a produção acadêmicocientífica, e envolve a avaliação de nossa própria atividade intelectual dentro do campo da educação, assim como da relevância da elaboração de "verdades" e dos compromissos que daí deveriam advir.

Como afirma Linhares (1997, p. 205):

Este parece constituir um dos maiores desafios que precisamos urgentemente enfrentar: o antagonismo entre a produção acadêmica, que se desenvolve progressivamente, e a escola pública fundamental, que não pára de se deteriorar.

Este estudo representa, pois, a intenção e o objetivo de buscar agrupar, organizar e analisar a produção acadêmica sobre a questão do professor, selecionada para apresentação em reuniões da SBPC, visando divulgar as principais perspectivas e tendências que as pesquisas científicas na área apontam. Nesse escopo de análise, o discurso manifesto na SBPC sobre a questão do professor apresenta-se, em face dos objetivos deste estudo, importante por: a) ser originário de entidade que congrega cientistas de todas as áreas de conhecimento; b) significar o pensamento de intelectuais diretamente envolvidos com o processo de produção de conhecimentos em educação; c) ser representativo da produção docente e discente, ou seja, de professores e alunos do ensino superior, de graduação e pósgraduação das várias regiões e instituições do país.

Historicamente, constata-se, no âmbito do discurso da comunidade acadêmico-científica, ${ }^{1}$ a relevância da SBPC no embate sobre a questão do professor (Candau, 1987; Carvalho; Salviato,1994; Carvalho et al., 1994, 1996).

Cabe perguntar:

- Continuaria a SBPC integrada à luta do movimento dos educadores sobre a questão do professor? Como se manifestou a respeito na 53 Reunião Anual em Salvador, no início do século XXl?

- Como politicamente se configura a origem territorial, institucional e de financiamento da produção científica? Como epistemologicamente se configuram as temáticas predominantes, assim como as orientações teórico-metodológicas da produção científica na área?

— Qual(ais) a(as) definição(ões) a comunidade acadêmico-científica, como individualidade (trabalhos de pesquisadores independentes), dá ao papel do professor e à sua formação?

- Qual a concepção de ciência e de educação subjacente à produção científica sobre a questão do professor apresentada na $53^{a}$ Reunião Anual da SBPC, em 2001, portanto, no início do século XXI?

- Como, histórica e comparativamente, essa produção manifestada no início de 2001, se revela em face da produção científica sobre a questão do professor manifestada na década de 1980?

A tentativa de resposta a qualquer dessas questões remete prioritariamente a uma questão de fundo, ou seja: 0 que é conhecimento científico e a que/quem ele serve e/ou deveria servir?

\section{Sobre os espaços/tempos do conhecer}

(...) Milênio vai, milênio vem, a ocasião é propícia para que os oradores de inflamado verbo discursem sobre os destinos da humanidade e para que os porta-vozes da ira de Deus anunciem o fim do mundo e o aniquilamento geral, enquanto o tempo, de boca fechada, continua sua caminhada ao longo da

1. Entende-se discurso da comunidade acadêmico-científica, conforme definido por Carvalho (1992): o discurso expresso por intelectuais, direta ou indiretamente ligados ao ensino superior, porém diretamente ligados ao saber de "alto nível". Esses estudiosos se organizam em entidades de cunho científico-político-cultural e posicionam-se, como coletividade ou individualidade, no âmbito da sociedade civil. 
eternidade e do mistério.

Verdade seja dita, não há quem resista: numa data assim, por mais arbitrária que seja, qualquer um sente a tentação de perguntar-se como será o tempo que será. E vá-se lá saber como será. Temos uma única certeza: no século XXI, se ainda estivermos aqui, todos nós seremos gente do século passado e, pior ainda, do milênio passado(...).

Eduardo Galeano

0 paradigma da ciência moderna impregnou as ciências humanas e sociais, adaptando seus procedimentos metodológicos de busca do conhecimento à racionalidade cognitivo-instrumental da ciência e da técnica.

A transição paradigmática, segundo Santos (1997), tem sido entendida de dois modos antagônicos: as promessas da modernidade não foram e nem podem ser cumpridas, se reduzidas as suas possibilidades às do capitalismo (pós-modernismo inquietante ou de oposição, p. 35); ou o que está em crise é a idéia da possibilidade da existência de uma racionalidade universal fundada numa instrumentalização científica, com objetivos "trans-históricos" a cumprir em direção a um projeto de emancipação humana (pós-modernismo reconfortante ou de celebração, p. 36).

Assumindo a primeira versão, Santos argumenta que o projeto sociocultural da modernidade se assenta em dois pilares fundamentais: o da regulação e o da emancipação. Ao pilar da regulação corresponderiam os princípios do Estado, do poder, do mercado e da instrumentalização científica. Ao pilar da emancipação corresponderiam os princípios da comunidade e a interpenetração de três lógicas e/ ou racionalidades: a estético-expressiva, a moral-prática e a cognitivo-instrumental. Argumenta, entretanto, sobre a colonização dos princípios correspondentes ao pilar da emancipação pelos princípios do mundo sistêmico e/ ou da regulação, que afastaram a ética e a estética da ciência, assim como a colonização do princípio da comunidade pelo mercado.
Como decorrência, tem-se a hipótese de que as patologias da modernidade se devem a processos de dissociação e racionalização que produzem a colonização do mundo vivido. Pergunta-se, então:

- Considerando tal processo de colonização como uma patologia, existiria uma terapia possível para ela? Estamos sofrendo um processo de patologia do saber?

A organização científica disciplinarizada instituiu-se no século XIX com a formação das universidades modernas, desenvolvendo-se com o incremento da pesquisa no século XX. Assim sendo, os tempos/espaços do conhecimento inscrevem-se nos tempos/espaços da universidade que, por sua vez, se inscreve na sociedade em seus processos de conhecer.

Santos (1989) destaca, nesse movimento, a necessidade da ocorrência de uma dupla ruptura epistemológica: da ruptura com o paradigma da ciência moderna para a emergência de um novo paradigma da ciência pósmoderna; e o da ruptura com a perspectiva da dicotomia entre o senso comum e o conhecimento científico. Assim, as duas rupturas rompem com a racionalidade cognitivo-instrumental da ciência e da tecnologia da modernidade, visto que propõem a atitude epistemológica que permite reconfigurar conhecimentos para além das regularidades propostas pela modernidade. Procuram, também, ultrapassar a concepção de que o conhecimento, para ser científico, precisa desconsiderar o senso comum, visto que o senso comum deverá ser recuperado, reconfigurado, tornado ciência e vice-versa.

Dessa forma, o novo paradigma, por meio da dupla ruptura epistemológica, propõe um conhecer enraizado na realidade e/ou nos espaços/tempos do cotidiano social, não se tratando, entretanto, de retomar a ambição de controlar e dominar o real (característica da ciência moderna), mas de exercer um pensamento que, sendo complexo, não é, necessariamente, difícil, mas capaz de tratar o real, de dialogar, de negociar com ele em sua comple- 
xidade e multidimensionalidade.

Se, por um lado, como o afirma Morin (2000), a fecundidade da disciplinaridade na história da ciência não tem que ser demonstrada, é evidente, visto que delimita um domínio de competência sem a qual o conhecimento se tornaria vago, assim como descobre e constrói um "objeto" digno de interesse para o estudo científico, por outro lado, tem-se que estar atento para o risco da hiperespecialização, pela qual e na qual as ligações e solidariedades de um "objeto" com outros “objetos" são negligenciadas, tendendo a dotar um campo do saber com espírito de proprietário que impede a circulação desse saber com outros saberes:

a história das ciências não é somente a da constituição e da proliferação das disciplinas, mas também a das rupturas de fronteiras disciplinares, de circulação de conceitos, de formação de disciplinas híbridas que acabam por se autonomizar (...). Dizendo de outro modo, se a história oficial da ciência é a disciplinaridade, outra história, que the é ligada e inseparável, é aquela da inter-trans-poli-disciplinaridade. (Morin, 2000, p. 68-69)

Assim, no paradigma emergente da ciência pós-moderna, derivado das chamadas ciências físico-naturais, porém não reduzido a elas, as disciplinas são plenamente justificadas se não ocultam as realidades globais, por exemplo, as ciências humanas e sociais que tratam o homem como ser psíquico e cultural, mas, também, como um ser biológico, de modo que "num sentido tudo é físico, mas, ao mesmo tempo, tudo é humano" (Morin, 2000, p. 77).

Deve-se, portanto, conceber um conhecimento "ecologizado", isto é, contextualizado, dialogicizado, problematizado. o professor?

E a educação e, nela, a pesquisa sobre

Discordamos de concepções que entendem a educação apenas como método organizador dos diferentes conteúdos/saberes em vista de uma formação global do educando, pois, sob a argumentação de sua não identificação como ciência, pretendem dar a ela, à educação, uma abertura maior, considerando-a, porém, como campo de aplicação das chamadas "ciências-mãe" e, portanto, sem "objeto" de estudo.

Assim, a concepção de ciência aqui esboçada e esposada é a da abordagem de ciência híbrida, não compartimentalizada, e, dessa forma, "trans-poli-disciplinarizada" e, portanto, transversalizada por saberes interseccionados, problematizados e contextualizados e isso não apenas como abordagem para a educação como ciência, mas para a ciência de modo geral, assim como para uma ciência educativa orientada pelo princípio da comunidade/coletividade, enfim, despatolo-gizada e/ou descolonizada do mundo sistêmico regulador e fecundada por uma racionalidade ética e estética da existência.

\section{- lugar da pesquisa sobre o professor na SBPC}

Retomando a questão inicialmente colocada - Continuaria a SBPC integrada à luta do movimento dos educadores sobre a questão do professor? Como se manifestou a respeito na $53^{\circ}$ Reunião Anual em Salvador, 2001, portanto, no início do século XXI? -, tem-se a indagação sobre a expressividade do setor educação na produção científica selecionada.

Considerando as áreas/campos do saber, nas quais foram classificados os trabalhos a serem apresentados como pôsteres, observase a representação de 92 delas, ${ }^{2}$ ou seja, nem todas as áreas/subáreas do conhecimento apresentaram e/ou tiveram trabalhos selecionados, assim como o fato de a área Educação - G.3.0

2. Ver In: REUNIÃO ANUAL DA SOCIEDADE BRASILEIRA PARA O PROGRESSO DA CIÊNCIA, 53, 2001. Salvador. Programa... Salvador: SBPC, 2001. 
estar representada de forma expressiva tanto na classificação genérica da área como por meio de mais sete subáreas. De um total de, aproximadamente, 4.780 trabalhos selecionados nas diversas áreas/campos do saber, 744 trabalhos pertenciam à área Educação, ou seja, quase 16\%. Dentre estes foram catalogados pelo Comitê Científico, como especificamente enfocando a Formação Inicial e Contínua de Professores (G.3.15), 60 trabalhos. Entretanto, uma leitura atenta aos resumos dos trabalhos da área G.3 - Educação e suas subáreas - evidencia que a quantidade de trabalhos que abordaram a questão do professor foi expressivamente maior, em torno de 310 resumos, ou seja, 7\% do total de resumos de pôsteres selecionados e 42\% do total de resumos da área Educação.

Se foi bastante expressiva a produção científica na área Educação e, nesta, o volume de pesquisas que abordam a questão do professor entre os pôsteres, o mesmo não se pode dizer com relação à chamada "parte nobre" da reunião anual da SBPC, visto que, das 38 Conferências apresentadas, apenas duas (5\%) eram referidas à área Educação, uma sobre o Ensino de Ciências e a outra sobre a Educação à Distância. Entretanto, nos simpósios e minicursos, a presença da área Educação voltou a ser expressiva, $16 \%$ no caso dos simpósios e 14\% no caso dos minicursos, com ênfase no caso dos simpósios de Ensino de Ciências e de Educação à Distância.

De modo geral, pode-se, portanto, concluir que sim, na SBPC o debate sobre a questão do professor está presente, manifestando-se não só pelos encontros e moções ali concretizados, como pelo acolhimento à produção científica da área Educação e, nesta, das pesquisas sobre o professor, apesar de seu posicionamento quase marginal em relação às conferências (5\%).

Porém, se estava presente nas pesquisas e debates a questão do professor, qual(ais) a(as) definição(ões) a comunidade acadêmico-científica, como individualidade (trabalhos de pesquisadores independentes), deu ao papel do pro- fessor e à sua formação? Como politicamente se configura a origem territorial, institucional e de financiamento da produção científica? Como epistemologicamente se configuram as temáticas predominantes, assim como as orientações teórico-metodológicas da produção científica na área? Qual a concepção de ciência, e de educação como ciência, presente nessas pesquisas e debates?

0 exame dos dados contidos nos resumos selecionados para a seção de pôsteres revela que, quanto ao cargo ou função, a predominância é de professores de instituições públicas de ensino, alunos de cursos de pós-graduação em universidades públicas e alunos de graduação, bolsistas de iniciação científica (Programa PIBIC/CNPq).

Quanto à origem territorial (Fig. 1), observou-se que os maiores percentuais são referidos às regiões Sudeste, com 34\%, e Nordeste, com 36\% das pesquisas apresentadas na seção de pôsteres, seguidas da região Sul, com $22 \%$, da região Norte, com $5 \%$, e da região Centro-Oeste com, apenas 3\%. A concentração da produção científica nas regiões Sudeste e Sul não surpreende em face do desenvolvimento socioeconômico e político-cultural das referidas regiões.

A surpreendente presença da região Nordeste, provavelmente, justifica-se pela proximidade geográfica com o Estado-sede da 53를 Reunião da SBPC, Salvador/BA, pertencente à região Nordeste. Tem-se que destacar a baixa representatividade das regiões Centro-Oeste e Norte.

Sobre a origem institucional (Fig. 2), observou-se que $80 \%$ das instituições são públicas, ou referidas a universidades federais (53\%) ou a universidades estaduais (28\%), conforme o gráfico ilustra. As universidades privadas representam $8 \%$, as faculdades integradas e os centros universitários públicos ou privados, aproximadamente, $1 \%$ e $2 \%$, sendo, portanto, inexpressiva a sua participação. Temse, então, que considerar o papel que as instituições universitárias públicas vêm desempe- 
nhando na pesquisa em educação e, nesta, na pesquisa sobre o professor, apesar do sucateamento a que elas (as universidades) têm sido submetidas pelas políticas neoliberais dirigidas ao ensino superior.

0 gráfico seguinte (Fig. 3) ilustra de modo contundente a participação das instituições públicas no incremento da pesquisa na área educacional, representando a rede de ensino pública, aproximadamente, $86 \%$ do total contra $13 \%$ da rede privada de ensino superior.
Com relação ao nível de ensino no qual o estudo/a pesquisa foi desenvolvido/a, observa-se a concentração de estudos no ensino fundamental, séries iniciais e finais, com, aproximadamente, 50\% dos casos, conforme o gráfico (Fig. 4) ilustra.

Destaca-se, ainda, a ênfase em estudos, sobre a questão do professor, dirigidos ao ensino superior, a saber: $28 \%$. Cumpre, entretanto, frisar a quase inexistência de estudos sobre o professor concernente ao ensino médio $(7,5 \%)$,

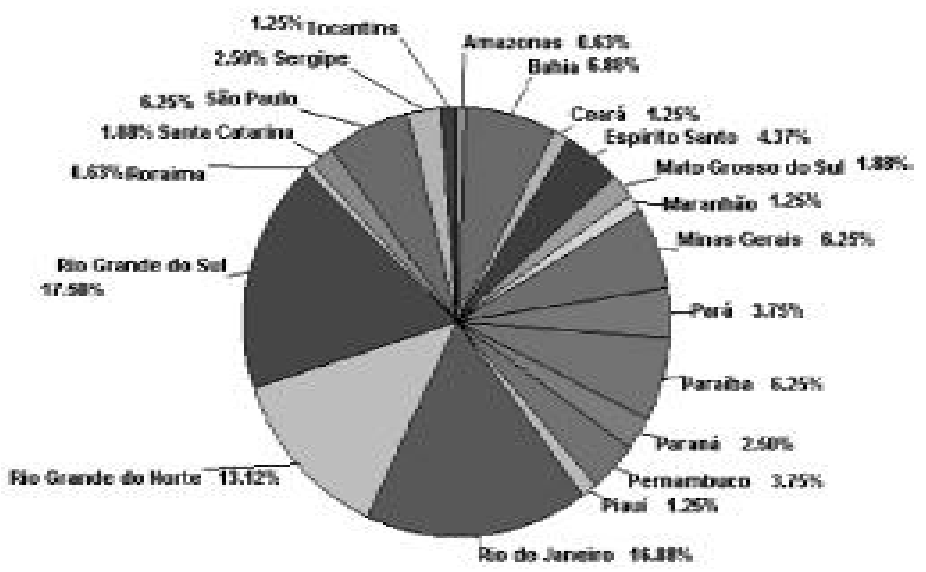

Fig. 1 - Origem territorial dos estudos/pesquisas

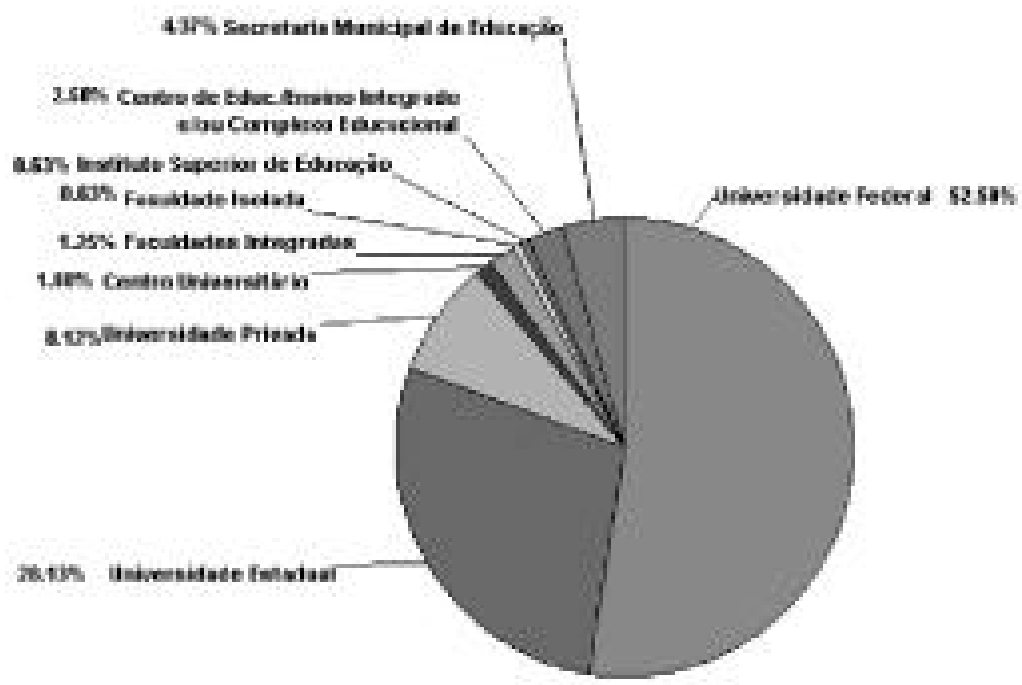

Fig. 2 - Origem institucional dos estudos/pesquisas 
educação infantil (5,6\%), educação de jovens e adultos $(1,9 \%)$ e educação básica, ou seja, que enfoquem a questão do professor da educação infantil ao ensino médio (aproximadamente $10 \%)$.

Sobre as temáticas predominantes (Fig. 5), manifestaram-se, nas pesquisas, as seguintes tendências de estudo e/ou categorias de análise: a identidade/profissionalidade docente, a formação inicial, a formação continuada e a prática pedagógica. A prática pedagógica foi a temática mais recorrente, apresentando várias subtemáticas e/ou direções de análise da prática pedagógica (pp), a saber: pp/abordagem didática e/ou saberes do professor; $p p /$ inovação metodológica; pp/utilização de tecnologias da informação e comunicação (T1Cs); pp/ interdisciplinaridade/transversalidade da abordagem didática; $p p /$ ação política e/ou formação da cidadania; pp/interação professor e alu-

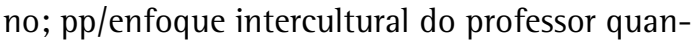
to ao gênero; pp/enfoque intercultural do pro-

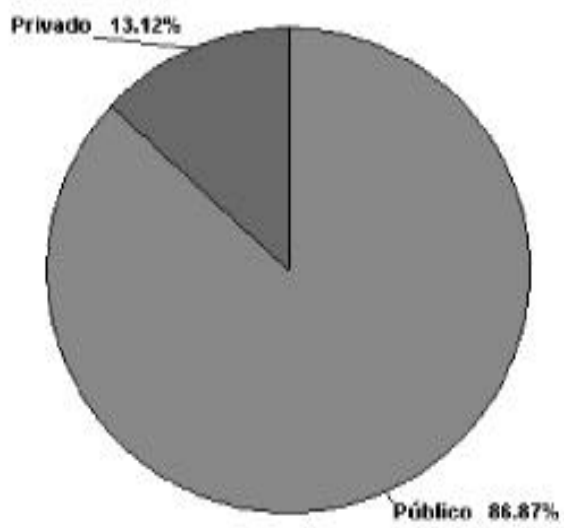

Fig. 3 - Rede de ensino pública ou privada dos estudos/pesquisas

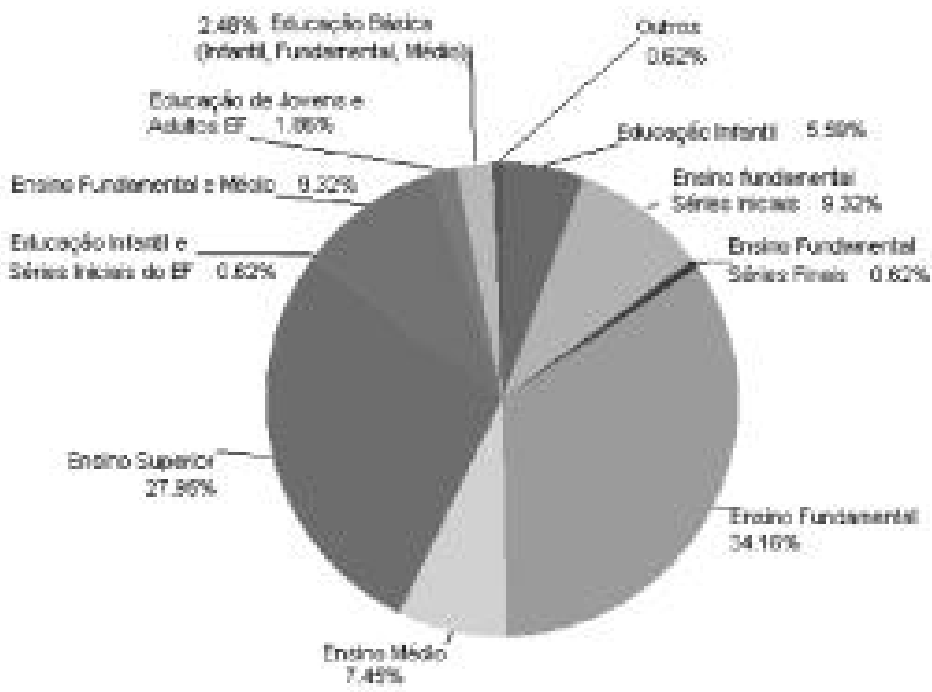

Fig. 4 - Nível de ensino de desenvolvimento dos estudos/pesquisas 
fessor quanto à raça, etnia; pp/enfoque intercultural do professor quanto a necessidades educativas especiais; $p p /$ relação teoria e prática; pp/integração ensino e pesquisa.

Observou-se que, aproximadamente, $60 \%$ das temáticas enfocadas nos estudos/pesquisas sobre a questão do professor foram dirigidas à prática pedagógica, com maior concentração no estudo da didática e dos saberes dos professores $(11,8 \%)$, da utilização das novas tecnologias da informação e comunicação $(9,9 \%)$, da relação teoria e prática $(8,1 \%)$, do enfoque intercultural quanto à questão de raça/ etnia, gênero e necessidades educativas especiais $(6,8 \%)$, da interdisciplinaridade/transdisciplinaridade (5,6\%), da inovação metodológica (5\%), da integração ensino e pesquisa (5\%).

As demais temáticas foram objeto de estudo de, aproximadamente, $40 \%$ das pesquisas apresentadas, na seguinte proporcionalidade: formação continuada (16,1\%), formação inicial $(15,5 \%)$ e a questão da identidade/ profissionalidade docente (8,7\%).

Com relação às áreas de conteúdo dos estudos/pesquisas (Fig. 6), observou-se a predominância, já esperada, da área de Pedagogia com 54\% dos casos. Destacaram-se, também, porém de forma menos expressiva, os estudos centrados na área de Ciências Biológicas e/ou Naturais, com 13\% dos casos. Destacou-se, ainda, a área de Informática (5\%). As demais áreas apresentaram percentual inexpressivo, ou seja, inferior a 5\%.

Sobre a orientação teórica predominante nos estudos, observou-se que mais de $60 \%$ dos estudos/pesquisas não explicitaram nenhuma orientação específica, sobressaindo, entre os que o fizeram, a explicitação da perspectiva sócio-histórica (13\%), a abordagem do professor como profissional reflexivo (8\%), o construtivismo (6\%), a teoria crítica (5\%). De modo geral, tomadas isoladamente, as orientações teóricas explicitadas, além das destacadas, apresentaram percentuais inexpressivos, entre menos de $1 \%$ e $3 \%$.

Essa distribuição, entretanto, é alterada quando são reunidas as orientações teóricas.

Considerando-se que, aproximadamente, $60 \%$ dos estudos não explicitaram a orientação teórica adotada, entre os estudos que o fizeram, aproximadamente 51\% dos estudos/ pesquisas apoiaram-se na perspectiva da teoria

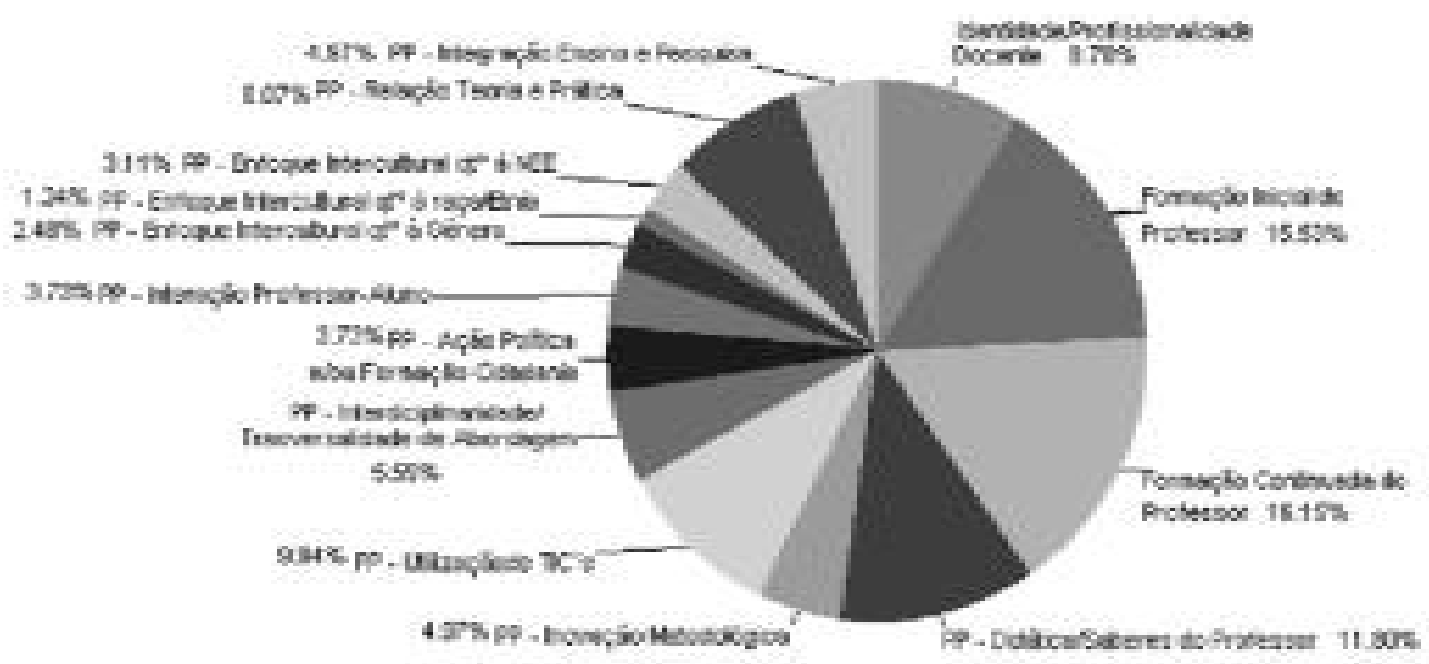

Fig. 5 - Temáticas dos estudos/pesquisas 
crítica, 19\% na perspectiva fenomenológicoexistencialista, $14 \%$ no enfoque objetivista e $11 \%$ na teoria pós-crítica (5\% foram agrupados como outra orientação), conforme ilustração abaixo (Fig. 7).

Com relação à orientação metodológica (Fig. 8), observou-se que, dentre os 161 estudos/pesquisas que a explicitaram, a maioria desenvolveu uma pesquisa-ação (35\%), seguida da pesquisa do tipo estudo de caso (18\%), pesquisa do tipo enquete e/ou estudo exploratório descritivo $(16,1 \%)$, pesquisa documental $(8,1 \%)$, pesquisa etnográfica e/ou socioantropológica $(6,2 \%)$. As demais pesquisas, por ordem percentual decrescente em relação ao número de casos, apresentaram a seguinte orientação metodológica: levantamento de opiniões e/ou survey $(4,3 \%)$, história de vida $(3,7 \%)$, pesquisa participante $(3,1 \%)$, estudo diagnóstico-avaliativo (1,9\%), análise do discurso $(1,2 \%)$, desenvolvimento de produto $(1,2 \%)$, história oral $(0,6 \%)$, estudo causal-comparativo $(1,2 \%)$. Outras abordagens e/ou orientações metodológicas não foram detectadas.

Sobre as agências financiadoras dos estudos/pesquisas e ou agências de fomento,

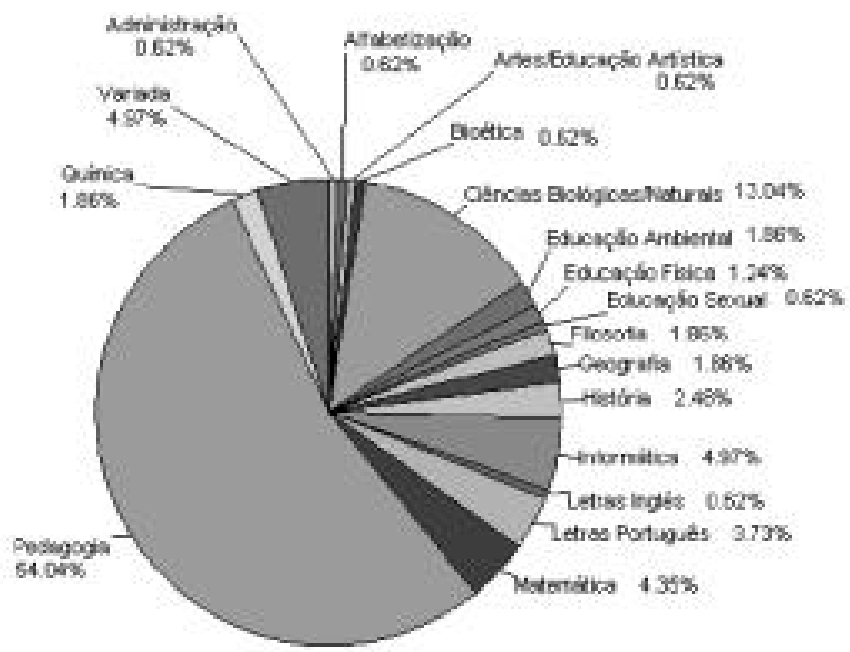

Fig. 6 - Áreas de conteúdo dos estudos/pesquisas

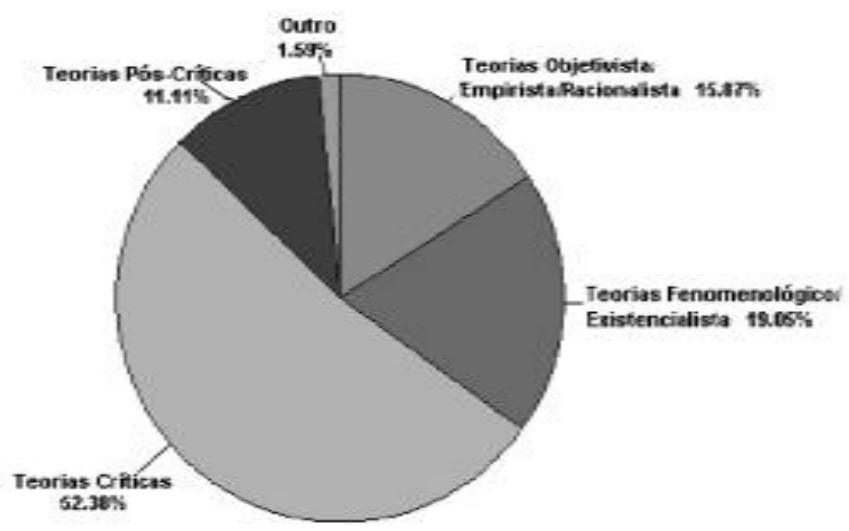

Fig. 7 - Orientação teórica dos estudos/pesquisas 
conforme o gráfico (Fig. 9) ilustra, observou-se que o principal responsável pelo auxílio financeiro citado foi o departamento de pesquisa da instituição de origem, seguido pela Capes e CNPq.

Retomando as questões colocadas na introdução do estudo, sobre se a SBPC, como entidade que congrega cientistas de todas as áreas do conhecimento, continuaria inserida no debate sobre a questão do professor e/ou ao incentivo à pesquisa na área educação e, nesta, à questão do professor, diríamos, como exposto anteriormente, que aparentemente sim. Esse envolvimento manifesta-se, à primeira vista, pelo elevado número de trabalhos selecionados para o evento versando sobre a temática do professor.

Com relação à configuração da origem territorial, institucional e de financiamento das pesquisas, assim como às temáticas e às orien-

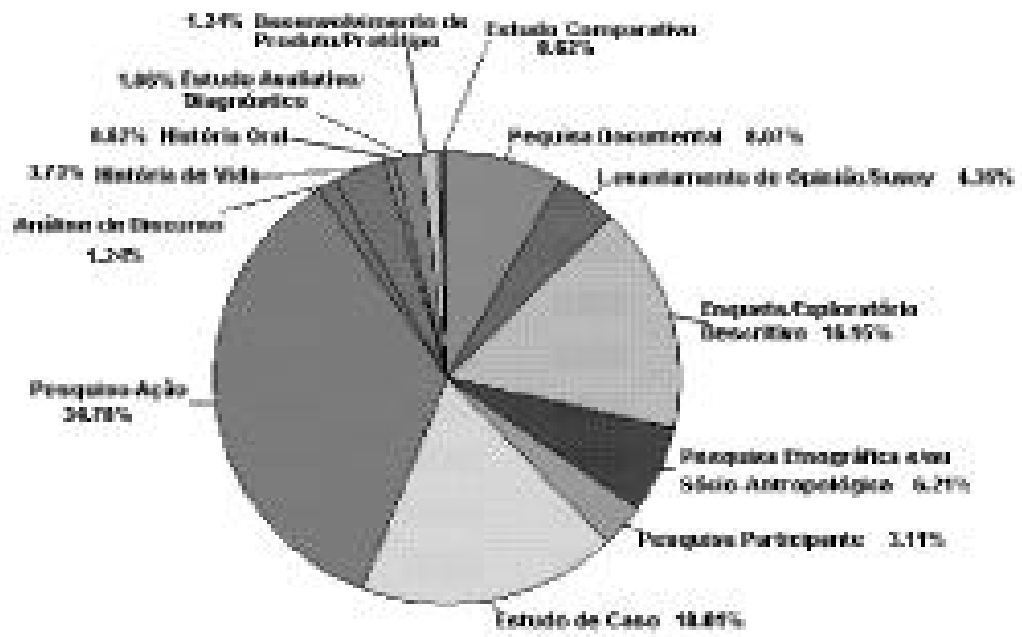

Fig. 8 - Orientação metodológica dos estudos/pesquisas

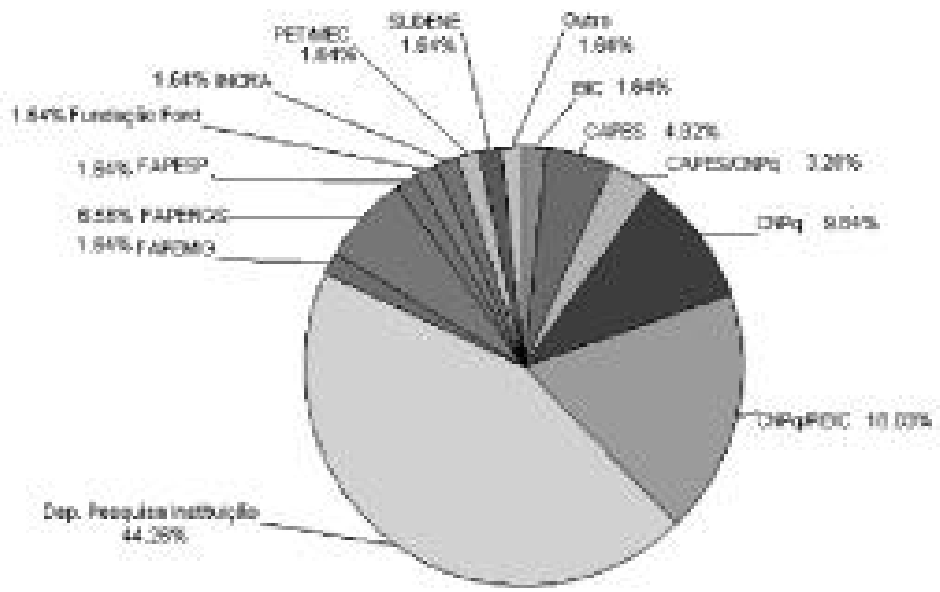

Fig. 9 - Agências/fontes financiadoras dos estudos/pesquisas 
tações teórico-metodológicas predominantes nessa produção, em síntese, observou-se que os estudos/pesquisas concentraram-se, em especial, no professor e na sua prática pedagógica no ensino fundamental e superior, destacandose os estudos voltados para o ensino fundamental com abordagem metodológica qualitativa na versão pesquisa-ação, com intervenção voltada para a prática pedagógica cotidiana nas escolas, com aporte teórico da pedagogia crítica.

A área de conteúdo predominante nos estudos veio a ser a da Pedagogia, revelandose, dessa forma, não apenas como espaço de aplicação de conhecimentos tranversalizados, mas como área que examina as questões do professor e sua prática pedagógica à luz do referencial teórico-crítico, com "objeto" próprio de estudo, o ensinar/aprender, e não apenas como campo de aplicação de saberes derivados das chamadas "ciências-mãe".

Com relação à origem territorial e institucional, destacaram-se as regiões Sudeste e Nordeste, esta última provavelmente em função da localização do evento (Salvador/BA), assim como a enorme presença das instituições públicas, sendo a questão do professor tematizada predominantemente por iniciativas ligadas às universidades públicas, federais e estaduais, que encontram, em si mesmas, as principais fontes financiadoras das pesquisas por meio de seus departamentos internos de pesquisas institucionais. Tal fato parece corroborar o pressuposto do cumprimento, por parte das instituições universitárias, do princípio da indissociabilidade entre as atividades de ensino, pesquisa e extensão. Mesmo não contando com dados sobre extensão, pela predominância da modalidade teórico-metodológica dos estudos (pesquisa-ação crítica, inserida no cotidiano da escola pública fundamental), diríamos que o tripé ensino-pesquisa-extensão foi a base de sustentação da tematização dos estudos/pesquisas sobre a questão do professor no início do século XXI, ano de 2001, na 53a Reunião Anual da SBPC.
Quanto à(s) definição(ões) que a comunidade acadêmico-científica, como individualidade (trabalhos de pesquisadores independentes), dá ao papel do professor e à sua formação e com relação à concepção de ciência e de educação subjacente à produção científica sobre a questão do professor apresentada na SBPC, em 2001, portanto, no início do século $X X 1$, diríamos que a produção científica apresentada, assim como as definições que os trabalhos de pesquisadores independentes, tomados em seu conjunto, dão ao papel do professor, à sua formação e prática, tendem para: a) a busca por parte dos pesquisadores, mesmo se apresentando como individualidades em suas iniciativas, do atendimento ao princípio da comunidade em seus estudos/pesquisas por meio da integração do saber ao fazer e/ou pela perspectiva de implementação de discursos práticos na vida cotidiana, visando, de certa forma, pela pesquisa-ação crítica, à "reinvenção" do cotidiano escolar; b) o atendimento aos pressupostos da dupla ruptura epistemológica, tanto de ruptura com o paradigma da ciência moderna, no qual a

(...) educação e as ciências humanas/sociais, de modo geral, tendiam a ser consideradas como ciência, quanto mais se aproximassem dos procedimentos empírico-formais característicos das ciências exatas/naturais, devido ao conceito predominante de unificação das ciências através da metodologia científica e à visão de ciência como conhecimento neutro, relacionado a regras metodológicas universais, aplicável a qualquer conteúdo, baseado em rígido controle de variáveis e teste de prova (...) (Carvalho, 1992, p. 81)

como de ruptura com a visão dicotômica entre conhecimento científico e senso comum, visto propor um conhecimento enraizado na realidade e/ou nos espaços/tempos do cotidiano social sem, entretanto, desconsiderar a multiplicidade de métodos possíveis de aborda- 
gem do "objeto" de estudo (Bachelard, 1975); c) a fuga da hiperespecialização ao levar em consideração os saberes de outras áreas, ao considerar as ligações e solidariedades entre o “objeto" de estudo da educação e, nesta, da questão do professor, com outros "objetos" e áreas/campos do saber.

\section{Sobre os lugares no tempo: análise comparativa do discurso atual com o da década de $1980^{3}$}

A questão colocada sobre como histórica e comparativamente a produção, manifestada no início do século XXI, ano de 2001, revela-se em face da produção científica sobre a questão do professor apresentada década de 1980, buscará elementos de resposta em estudos da mesma autoria (Carvalho et al., 1994; Carvalho; Salviato, 1994).

Considerando, como frisado na parte introdutória, que a análise sobre a questão do professor importa tanto pela sua especificidade epistemológica, como por revelar uma concepção político-filosófica, os resultados contidos nos Anais das Reuniões da SBPC em toda a década de 1980, com relação à formação, prática pedagógica, organização pedagógica e exercício do magistério, além de ser em número reduzido, revelando ser uma temática presente, mas não predominante, no âmbito da SBPC na década de 1980 , evidenciou uma bifurcação de caminhos e/ou uma dupla perspectiva: a perspectiva epistemológica e a socioeconômica e política. Assim sendo, dir-seia que a análise sobre a questão do professor expressa na década de 1980 permitiu evidenciar nos discursos, de forma bastante clara, mas nem sempre interpenetradas, as dimensões socioeconômicas, políticas e a epistemológica, em sua versão essencialmente metodológica.

Com relação à dimensão socioeconômica e política, as sínteses parciais (por pesquisador) permitiram constatar as seguintes evidências: a) relação teoria e prática como forma de levar o futuro professor a contextualizar seu trabalho e imprimir sentido transformador na melhoria da qualidade de ensino, em favor das camadas populares (Berger, 1980); b) necessidade de maior integração da escola de formação de professores com a comunidade, visando a uma socialização pedagógica, didática e a uma formação profissional mais política (Paoli, 1982); c) maior vínculo da parte prática com a parte instrumental do curso de formação de professores, tentando tornar esta última mais reflexiva e dialógica (Miguel, 1983); d) relação entre competência técnica e compromisso político no processo de formação do professor, mediante maior embasamento em fundamentos da educação e na parte instrumental do currículo, para subsidiar uma prática mais conseqüente (Oliveira, 1986); e) constatação de que as deficiências nos cursos de formação de professores não serão solucionadas apenas com mudanças curriculares, pois os fatores de ordem socioeconômica e política interferem, sendo determinantes e determinados no processo (prestígio do professor, remuneração, política educacional, etc.) (Penin, 1980; Vilela, 1988); f) possibilidade de uma prática política do professor, como agente de transformação social, auxiliar na superação e prevenção de problemas pedagógicos, familiares e comunitários do aluno (Eluf, 1980); g) constatação de que a especialização ou nível de estudos avançados é menos determinante do aproveitamento do aluno que o fator experiência e prática social (Marques, 1980); h) discordância quanto ao fato de a origem socioeconômica do professor ser fator limitador de sua práxis político-pedagógica, visto que essa origem pode ser superada por sua formação e prática polí-

3. As evidências extraídas das sínteses/resumos dos estudos da década de 1980 não são possíveis de serem explicitadas por meio de gráficos e percentuais em face do reduzido número de casos, assim como o elevado número de trabalhos apresentados no discurso atual dificulta a apresentação de sínteses descritivas parciais por estudo. Dessa forma, a análise comparativa ocorre por meio de formas distintas de apresentação dos dados, o que limita, mas não impede uma comparação parcial entre os discursos. 
tico-dialógica (Azevedo,1983); i) relação entre trabalho pedagógico, atualização e compromisso com a realidade social, contrapondo-se a uma perspectiva de treinamento em serviço, em que predominem o tecnicismo e a padronização de conteúdos e procedimentos (Bueno, 1985; Guimarães, 1985).

Com respeito à dimensão epistemológica em sua versão essencialmente metodológica, as sínteses parciais permitiram constatar as seguintes evidências: a) ênfase em pesquisas de avaliação curricular e propostas de alteração nesse sentido, por exemplo: estruturação curricular em três períodos (sensibilização, laboratório e assunção da responsabilidade docente) ou três domínios (acadêmico, pedagógico e prático) (Santos Filho, 1980); b) propostas de revisão da seqüência dos conteúdos curriculares de forma a garantir coerência interna (Baltar, 1981); c) revisão das licenciaturas de modo a aproximá-las do que deve ser ensinado em nível de $1^{\circ}$ e $2^{\circ}$ graus; domínio do conteúdo associado à compreensão, elaboração e transmissão do currículo de escolas de $1^{\circ}$ e $2^{\circ}$ graus (Santos Filho, 1982; Araújo, 1982); d) integração entre agências formadoras de recursos humanos para a educação, igualando o nível e diminuindo disparidades (Aragão, 1982); e) integração permanente entre formação pedagógica e conteúdos específicos dos cursos de formação de professores (Romano, 1983); f) maior ênfase e/ ou aprofundamento de estudos nos conteúdos específicos (Faria, 1985); g) revitalização dos cursos normais (atual ensino médio, antigo $2^{\circ}$ grau), da escola normal superior e dos cursos de licenciatura, enfim dos cursos de formação do professor, em suas estratégias e conteúdos (Vilela, 1988; Pinto, 1987); h) relação maior entre estágios curriculares, com referenciais teóricos transmitidos academicamente no interior dos cursos de formação dos professores (Giannaccine; Reymão, 1989); i) prática social do professor como reflexo das condições de ensino e/ou de sua formação pedagógica (Carvalho, 1981); j) dificuldades encontradas pelos docentes quanto a diversas situações pedagógicas como reflexo de sua formação (Bueno, 1985); l) possibilidade de desenvolvimento da criatividade do professor por meio de uma metodologia mais interativa com os colegas (Alencar; Leith, 1986); m) melhoria do desempenho do professor pelo treinamento que supere o ensino expositivo em direção a um ensino mais ativo e experimental (Souza Filho, 1988); n) importância de treinamentos em serviço de natureza pedagógica e em conteúdos específicos, para melhoria do desempenho no exercício do magistério (Bastos, 1989).

Assim sendo, a análise comparativa entre os discursos sobre a questão do professor na década de 1980 e no início do século XXI, ano 2001, revela: um aumento extraordinário do número de trabalhos (estudos/pesquisas) que tematizam a questão do professor, visto que, em dez anos (década de 1980), o número de trabalhos publicados nos anais das reuniões anuais da SBPC foi de 36 , ao passo que, em apenas uma reunião (a 53를 Reunião Anual da SBPC/2001), o número de trabalhos selecionados para apresentação na forma de pôsteres que tematizaram a questão do professor foi, aproximadamente, de 310 , excluindo-se os de Ensino de Física, que, não se sabe por qual critério, não foram inscritos na área Educação. Portanto, um crescimento de 36 para 310 estudos/pesquisas, ou seja, de aproximadamente $1.000 \%$; a predominância, na década de 1980 , do enfoque teórico-metodológico de estudos exploratório-descritivos, quanti-qualitativos, em contraposição à predominância de estudos com enfoque de pesquisa-ação crítica, visando à intervenção no cotidiano escolar, parecendo essa tendência indicar uma mudança paradigmática no enfoque dos estudos voltados para a temática da questão do professor; uma mudança de vetor e/ou de direção dos estudos.

A categoria e/ou temática mais enfatizada na década de 1980 foi a formação inicial do professor, representando, aproximadamente, 65\% dos estudos, seguida pela formação continuada com $20 \%$, pela identidade/ 
profissionalidade docente com $8 \%$ e prática pedagógica com 8\%. A comparação com os estudos/pesquisas desenvolvidos no início do século XXI, ano 2001, revela uma inversão, ou seja, $60 \%$ dos estudos/pesquisas enfocaram a prática pedagógica em variadas acepções e/ou perspectivas, parecendo indicar a alteração da crença do potencial formativo e central/ determinante dos cursos de formação inicial de professores. Dito de outra forma, da crença de que os cursos de formação inicial de professores seriam centrais/determinantes na produção de uma escola qualitativamente melhor, para a crença de que a escola e seus agentes/ agenciamentos em redes tecidas no cotidiano escolar, e para além dele, seriam o principal campo de possibilidades de transformação da escola e de suas práticas.

\section{Da negação dos espaços/ tempos nas pesquisas sobre 0 professor}

Conclui-se que faltou aos cientistas que apresentaram trabalhos sobre a temática da questão do professor nas reuniões da SBPC, na década de 1980, uma visão integradora entre competência técnica e compromisso político, ou seja, entre as questões acadêmico-curriculares e as relativas ao pedagógico referido ao político social. A problemática do "fazer" apareceu desvinculada da problemática do "por que fazer”. Por sua vez, os estudos/pesquisas apresentaram-se sem uma tematização coletiva e se expressaram como individualidades, portanto, referidos a si próprios.

Em 2001, observou-se, quanto à tematização coletiva, a mesma perspectiva. Já com relação à dicotomia entre o técnico e o político, foi visto que, apesar de a maioria dos estudos/pesquisas manterem a dicotomia, parte deles dirigiu-se a uma perspectiva integrada entre "o fazer", o "como fazer" e o "por que fazer”. Destaca-se, em certa medida, na produção científica de 2001, um desejo de reinvenção do cotidiano escolar, baseado nas "artes do fazer" (Certeau, 2001). Cumpre, entretanto, frisar que, de modo geral, a produção científica se efetiva, ainda, na dicotomia entre os lugares e os tempos da ciência moderna.

Qualquer estatuto de análise em sua relação com o objeto de estudo é conseqüência de uma rede de intercâmbios sociais, profissionais e textuais. Os trabalhos dos pesquisadores como autores, como individualidades, ao não serem conectados ao trabalho coletivo no qual se inscrevem, assim como ao apresentarem o objeto de seu discurso isolado de sua gênese histórica (tempo), fazem com que o autor ocupe não um espaço, mas um lugar que lhe é próprio e que se caracteriza pela não integração tempo/espaço.

De acordo com Certeau (2001, p. 201),

Um lugar é a ordem (seja qual for) segundo a qual se distribuem elementos nas relações de coexistência (...). Aí impera a lei do "próprio": os elementos considerados se acham uns ao lado dos outros, cada um situado num lugar "próprio" e distinto que o define.

\section{E, mais adiante:}

Existe espaço sempre que se tomam em conta vetores de direção, quantidades de velocidade e a variável tempo (...). Em suma, o espaço é um lugar praticado. (p. 202)

Assim, os espaços são ações de sujeitos históricos. Uma universidade ou academia geométrica e arquitetonicamente definida é transformada em espaço pelos professores, pesquisadores, alunos e outros agentes e suas práticas discursivas que transformam incessantemente lugares em espaços ou espaços em lugares. Os espaços exibem operações que permitem percursos, passagens, intercâmbios, trocas, compartilhamentos e não apenas a determinação da "lei de um lugar próprio", de autoria marcada e/ou do individualismo brilhante do 
pesquisador solitário que cerca, mesmo em grupo, o conhecimento e segue o modelo da ordem dos lugares, coerente com o discurso científico moderno.

A perspectiva dos lugares, e não dos espaços, aparece de forma recorrente mais na década de 1980, apesar de estar bastante presente na produção apresentada em 2001. Os discursos expressos nos estudos/pesquisas parecem, cada um, ocupar um "lugar próprio" e isolado que não permite a sua acepção como paisagem, conjunto tematizado ou conjunto da obra sobre a questão do professor. Não se vislumbra uma tessitura temática coletiva com gênese nos espaços e tempos da academia em sua relação com a realidade social e, nesta, da realidade da educação no Brasil, por mais que tenhamos nos esforçado para compor uma "rede" de significados entre eles.

Mesmo os estudos/pesquisas apresentando, do ponto de vista teórico-metodológico, uma perspectiva progressista e/ou de potencial transformador/emancipador, pela predominância do enfoque da pesquisa-ação crítica, algumas questões se impõem à guisa de consideração a todos nós que produzimos pesquisas negando os espa- ços/tempos da ciência e da educação:

- Assim como se apresenta, fundada no "lugar" e na "autoria", quais as possibilidades da pesquisa-ação ou da teoria crítica ser uma prática discursiva que altere as "artes de fazer" o cotidiano escolar?

- Em que medida a academia, produzida como lugar, possibilitará a emergência do princípio de comunidade e facilitará o intercâmbio, as trocas, o compartilhamento, a tessitura de redes de conhecimento entre ela e a educação, na escola e na sociedade?

- A universidade pública, responsável pela quase totalidade da pesquisa sobre a educação e, nela, sobre a questão do professor, apresenta-se como instituição em comunhão coletiva com outras instituições e/ou movimentos sociais, no sentido de tematizar coletivamente sua produção, utilizá-la para rever suas práticas e produzir alternativas coletivamente orientadas para si, para a escola pública de modo geral e para a sociedade?

- Na verdade, avançam a sociedade, a educação, a escola pública no Brasil ou cresce a academia e, nesta, o lugar do discurso acadêmico-científico?

\section{Referências bibliográficas}

ALENCAR, E. M. L. S.; LEITH, D. S. Avaliação de um programa de treinamento de criatividade por professores do ensino de primeiro grau. In: REUNIÃO ANUAL DA SOCIEDADE BRASILEIRA PARA O PROGRESSO DA CIÊNCIA, 38., 1986, Curitiba. Anais... São Paulo: Guaru, 1986.

ARAGÃO, R. et al. A percepção institucional e do sujeito em relação ao curso de licenciatura. In: REUNIÃO ANUAL DA SOCIEDADE BRASILEIRA PARA 0 PROGRESSO DA CIÊNCIA, 34., 1982, São Paulo. Anais.... São Paulo: Guaru, 1982.

ARAÚJO, A . P. A formação pedagógica na licenciatura plena em matemática: um estudo avaliativo na Universidade Federal do Rio Grande do Norte. In: REUNIÃO ANUAL DA SOCIEDADE BRASILEIRA PARA 0 PROGRESSO DA CIÊNCIA, 34., 1982, São Paulo. Anais.... São Paulo: Guaru, 1982.

AZEVEDO, J. L. et al. Professor do ensino elementar: prática e formação. In: REUNIÃO ANUAL DA SOCIEDADE BRASILEIRA PARA O PROGRESSO DA CIÊNCIA, 35., 1983, Belém. Anais... São Paulo: Guaru, 1983.

BACHELARD, G. O novo espírito científico. Lisboa: Edições 70, 1975.

BALTAR, M. J. Avaliação da coerência interna do currículo de um curso de pedagogia. In: REUNIÃO ANUAL DA SOCIEDADE BRASILEIRA PARA O PROGRESSO DA CIÊNCIA, 33., 1981, Salvador. Anais... São Paulo: Monsanto, 1981. 
BASTOS, C. R. V. et al. Avaliação dos níveis de desempenho de docentes em ciências do 1ํ grau após três anos de reciclagem. In: REUNIÃO ANUAL DA SOCIEDADE BRASILEIRA PARA 0 PROGRESSO DA CIÊNCIA, 41., 1989, Porto Alegre. Anais... São Paulo: Guaru, 1989.

BERGER, M. A . Uma abordagem de estágio em prática de ensino de 1ํgrau. In: REUNIÃO ANUAL DA SOCIEDADE BRASILEIRA PARA 0 PROGRESSO DA CIÊNCIA, 32., 1980, Rio de janeiro. Anais... São Paulo: Monsanto, 1980.

BUENO, S. M. V. Treinamento didático e reciclagem aos docentes de uma escola. In: REUNIÃO ANUAL DA SOCIEDADE BRASILEIRA PARA O PROGRESSO DA CIÊNCIA, 37., 1985, Belo Horizonte. Anais... São Paulo: Guaru, 1985.

CANDAU, V. M. F. (Org.). Novos rumos da licenciatura. Brasília: INEP, 1987.

CARVALHO, J.M. A formação do professor e do pesquisador, em nível superior, no Brasil: análise histórica do discurso do governo e da comunidade acadêmico-científica (1945-1964). 1992. Tese (Doutorado em Educação) - Faculdade de Educação, Universidade Federal do Rio de Janeiro, Rio de Janeiro, 1992.

CARVALHO, J. M.; SALVIATO, M.L. A análise do conteúdo do discurso da comunidade acadêmico-científica sobre o processo de formação do professor na década de 80. Relatório Final de Pesquisa. Vitória: DDPE/PPGE-PRPPG/UFES, 1994.

0 professor e o pesquisador no período populista. Cadernos de Sociologia - Universidade e Pesquisa, Porto Alegre, n. 8, p. 69-88, 1988.

CARVALHO, J. M. et al. A questão do professor no discurso da SBPC, na década de 80. Cadernos de Pesquisa da UFES, Vitória, n. 3, p. 40-47, 1994. 51, 1996.

A trajetória da formação do professor no Brasil: uma síntese. Cadernos de Pesquisa do PPGE/UFES, Vitória, n. 2, p. 36-

CARVALHO, M. J. V. Atribuições de causalidade feitas pelo professor de $1^{\circ}$ e $2^{\circ}$ graus da rede estadual de ensino paulista às condições de ensino e à associação da categoria profissional. In: REUNIÃ̃o ANUAL DA SOCIEDADE BRASILEIRA PARA 0 PROGRESSO DA CIÊNCIA, 33., 1981, Salvador. Anais... São Paulo: Monsanto, 1981.

CERTEAU, M. A invenção do cotidiano. 1. Artes de fazer. 6ª ed. Petrópolis: Vozes, 2001.

ELUF, M. L. K. 0 papel do professor como interventor na educação de base. In: REUNIÃO ANUAL DA SOCIEDADE BRASILEIRA PARA 0 PROGRESSO DA CIÊNCIA, 32., 1980, Rio de Janeiro. Anais... São Paulo: Monsanto, 1980.

FARIA, M. F. Competências básicas do professor que orienta as atividades de Educação Física no $1^{0}$ segmento do $1^{0}$ grau. In: REUNIÃO ANUAL DA SOCIEDADE BRASILEIRA PARA O PROGRESSO DA CIÊNCIA, 37., 1985, Belo Horizonte. Anais... São Paulo: Guaru, 1985.

GALEANO, E. Um convite ao vôo. Disponível em: <http:www.zonanon.com/plural/forumsocialmundial/textos.htm>. Acesso em: 15 fev. 2002

GIANNACCINE, A. ; REYMÃO, A . E. N. A relação teórico-prática nos estágios: a insuficiência do ensino acadêmico. In: REUNIÃO ANUAL DA SOCIEDADE BRASILEIRA PARA 0 PROGRESSO DA CIÊNCIA, 41.,1989, Porto Alegre. Anais... São Paulo: Guaru, 1989.

GUIMARÃES, E. C. S. Atualização permanente do professor como estratégia para a melhoria do ensino de ciências. In: REUNIÃo ANUAL DA SOCIEDADE BRASILEIRA PARA 0 PROGRESSO DA CIÊNCIA, 37., 1985, Belo Horizonte. Anais... São Paulo: Guaru, 1985.

LINHARES, C. F. A escola e seus profissionais: tradições e contradições. Rio de Janeiro: Agir, 1997.

MARQUES, E. A. 0 professor e sua influência sobre os alunos. In: REUNIĨO ANUAL DA SOCIEDADE BRASILEIRA PARA 0 PROGRESSO DA CIÊNCIA, 32., 1980, Rio de Janeiro. Anais... São Paulo: Monsanto, 1980. 
MIGUEL, A. et al. A prática de ensino e a didática. In: REUNIÃO ANUAL DA SOCIEDADE BRASILEIRA PARA 0 PROGRESSO DA CIÊNCIA, 35., 1983, Belém. Anais... São Paulo: Guaru, 1983.

MORIN, E. Articular os saberes. In: ALVES, N.; GARCIA, R. L. 0 sentido da escola. Rio de Janeiro: DP\&A, 2000. p. 65-80.

OLIVEIRA, E. F. M. A formação do educador e a pedagogia crítico-social dos conteúdos. In: REUNIÃO ANUAL DA SOCIEDADE BRASILEIRA PARA 0 PROGRESSO DA CIÊNCIA, 38., 1986, Curitiba. Anais... São Paulo: Guaru, 1986.

PAOLI, S. M. C. Formação de professores e monitores através da participação e da gestão da unidade educacional. In: REUNIÃo ANUAL DA SOCIEDADE BRASILEIRA PARA O PROGRESSO DA CIÊNCIA, 34., 1982, São Paulo. Anais... São Paulo: Guaru, 1982.

PENIN, S. T.S. A práxis do professor e suas relações com a satisfação/insatisfação no trabalho. In: REUNIÃO ANUAL DA SOCIEDADE BRASILEIRA PARA O PROGRESSO DA CIÊNCIA, 32., 1980, Rio de Janeiro. Anais... São Paulo: Monsanto, 1980.

PINTO, F. C. F. et al. Subsídios ao pensamento e à ação com vistas a uma nova política para o curso de formação de professores. In: REUNIĨO ANUAL DA SOCIEDADE BRASILEIRA PARA 0 PROGRESSO DA CIÊNCIA, 40., 1988, São Paulo. Anais... São Paulo: Guaru, 1988.

REUNIÃO ANUAL DA SOCIEDADE BRASILEIRA PARA O PROGRESSO DA CIÊNCIA, 53., 2001, Salvador. Programa... Salvador: SBPC, 2001.

ROMANO, A . P. et al. Notas sobre o encontro nacional de prática de ensino. In: REUNIÃO ANUAL DA SOCIEDADE BRASILEIRA PARA 0 PROGRESSO DA CIÊNCIA, 35., 1983, Belém. Anais... São Paulo: Guaru, 1983.

Pela mão de Alice: 0 social e o político na pós-modernidade. São Paulo: Cortez, 1997.

Introdução a uma ciência pós-moderna. Rio de Janeiro: Graal, 1989.

SANTOS FILHO, J. C. Domínio da formação inicial: uma proposta curricular para sua formação prática. In: REUNIĨO ANUAL DA SOCIEDADE BRASILEIRA PARA O PROGRESSO DA CIÊNCIA, 32., 1980, Rio de Janeiro. Anais... São Paulo: Monsanto, 1980.

Articulação entre os diferentes domínios da formação inicial do professor. In: REUNIÃO ANUAL DA SOCIEDADE BRASILEIRA PARA O PROGRESSO DA CIÊNCIA, 34., 1982, São Paulo. Anais... São Paulo: Guaru, 1982.

SOUZA FILHO, A. F. Treinamento de professores e sua aplicação concomitante no ensino do $1^{\circ}$ grau. In: REUNIÃO ANUAL DA SOCIEDADE BRASILEIRA PARA 0 PROGRESSO DA CIÊNCIA, 40., 1988, São Paulo. Anais... São Paulo: Guaru, 1988.

VILLELA, H. A primeira escola normal do Brasil: sua retrospectiva histórica. In: REUNIÃO ANUAL DA SOCIEDADE BRASILEIRA PARA O PROGRESSO DA CIÊNCIA, 40., 1988, São Paulo. Anais... São Paulo: Guaru, 1988.

Recebido em 16.05 .02

Aprovado em 10.10 .02

Janete Magalhães Carvalho é professora no PPGE/CP/UFES. Doutora em Educação pela UFRJ. Líder de grupo de pesquisa UFES/ CNPq. Co-autora da série Estado do Conhecimento, n. 6 — Formação de Professores no Brasil (1990-1998). Brasília: MEC/NEP/ COMPEd, 2002. Tem participado de coletâneas e publicado artigos sobre a questão do professor. 